\title{
Metáfora é diálogo: uma proposta de interface
}

\author{
Kári Lúcia Forneck* \\ Jorge Campos da Costa**
}

\begin{abstract}
Resumo
Neste estudo, pretende-se desenhar uma abordagem da metáfora na interface metateórica (COSTA, 2007). Pretende-se ilustrar como, por meio do diálogo interdisciplinar, novas abordagens para a metáfora podem ser construídas. Para tanto, de um lado, apresentam-se os fundamentos da Pragmática que explicam como se processam os enunciados metafóricos e, de outro, apresentam-se achados em Neurociência que, por sua vez, descrevem, via coarse-coding hypothesis, os correlatos neurais desse processamento. Postas em diálogo, dessas diferentes áreas emergem propriedades complexas que podem contribuir para o aprofundamento do potencial descritivo e explanatório da abordagem interdisciplinar. Além disso, pode-se também reacender e complexificar as possibilidades de diálogo entre teorias, à medida que propriedades complexas interagem entre si.
\end{abstract}

Palavras-chave: Metáfora. Interface metateórica. Teoria das implicaturas conversacionais. Teoria da relevância. Neurociência.

\section{Considerações iniciais}

Talvez por ser, como bem sugere Davidson (1984, p. 245), "o sonho da linguagem" de muitos pesquisadores, muitos tratados sobre metáfora têm sido produzidos. De um lado, por exemplo, há quem conceba a metáfora como um elemento ornamental, em especial, da linguagem poética, tal como concebeu Aristóteles; de outro, por sua vez, há quem argumente que o pensamento humano é moldado essencialmente por raciocínios metafóricos.

Nessa complexa configuração, o estatuto da metáfora pode ser construído no escopo de uma disciplina, assumindo então as propriedades da área em que esteja sendo desenhado. Nesse caso, pode a metáfora ser considerada, por exemplo, uma

\footnotetext{
* Professora do curso de Letras do Centro Universitário UNIVATES e doutoranda do Programa de Pós-Graduação em Letras da Pontifícia Universidade Católica do Rio Grande do Sul (PUCRS). E-mail: $<$ kari@univates.br>.

** Professor do Programa de Pós-Graduação em Letras da Pontifícia Universidade Católica do Rio Grande do Sul (PUCRS). E-mail: <jcampos@pucrs.br>.
} 
realização da linguagem natural, um fenômeno cognitivo ou fruto de processamento neurológico. Por outro lado, pode uma abordagem da metáfora ser construída na interface (COSTA, 2007), agregando as propriedades das disciplinas em diálogo e revisitando os fundamentos dessas disciplinas a partir da interdisciplinaridade. Nessa perspectiva, novos desenhos teóricos e metateóricos podem ser construídos para uma análise mais sofisticada da metáfora.

A fim de ilustrar a possibilidade de um estudo interdisciplinar, desenharemos a metáfora em duas áreas com escopo distinto, a saber: Pragmática e Neurociência. $\mathrm{Na}$ perspectiva pragmática, assumiremos duas teorias que, embora partilhem a mesma base epistemológica, entendem a metáfora sob pontos de vista divergentes. De um lado, a Teoria da Implicaturas Conversacionais de Grice (TIG) (1975a; 1975b), para quem as metáforas são entendidas como violações de máximas conversacionais; de outro, a Teoria da Relevância (TR), de Sperber e Wilson (1995, 2008) e Wilson e Sperber (2012) que incorporou à Pragmática aspectos cognitivos não apresentados nos estudos prévios, estabelecendo uma interface entre Linguística e Ciências Cognitivas. Na perspectiva neurocientífica, assumiremos a coarse-coding hypothesis (BEEMAN, 1998; JUNG-BEEMAN, 2005), que explica os padrões de ativação do hemisfério esquerdo (HE), área tipicamente associada ao processamento da linguagem, e do hemisfério direito (HD), área recrutada quando são necessárias associações semânticas mais complexas, como em enunciados metafóricos.

Assumidas as teorias em diálogo, traçamos as questões de análise: em que medida os fundamentos linguísticos têm sido utilizados como ponto de partida para delinear os experimentos com $\mathrm{fMRI}$ ? $^{1} \mathrm{E}$, em contrapartida, em que medida os estudos com neuroimagem podem reacender o diálogo entre hipóteses defendidas pela tradição linguística?

Ao problematizarmos essas questões, pretendemos ampliar as possibilidades do tratamento teórico da metáfora, através da proposição de um diálogo interdisciplinar.

Para tanto, dividiremos nossa análise em três seções: na primeira, a metáfora será desenhada na perspectiva pragmática, via TIG e TR; na segunda, serão apresentados três estudos com neuroimagem comumente referenciados na bibliografia da área, a fim de descrever o modo pelo qual os correlatos neurais são recrutados durante o processamento desses enunciados; por fim, na seção final, 
será proposto o diálogo entre as áreas, no intuito de complexificarmos o tratamento da metáfora, numa abordagem metateórica e também teórica. Metateórica, em razão de desenharmos a metáfora numa perspectiva terceira, interdisciplinarmente construída, nos fundamentos da Pragmática e da Neurociência. Teórica, uma vez que a partir desse diálogo interdisciplinar podemos, também, repensar os próprios fundamentos das teorias em diálogo.

\section{A metáfora na mente: a natureza dos conceitos metafóricos}

O modelo inferencial de Grice (1975a), descrito pela Teoria das Implicaturas Conversacionais (TIG), tem sido considerado a base da análise da linguagem natural, especialmente no que diz respeito aos significados implícitos da conversação (NEALE, 1992).

Entre outras, a principal contribuição da TIG diz respeito à tentativa de diferenciar o que uma sentença $\mathrm{S}$ significa, o que um falante $\mathrm{F}$ disse em uma ocasião particular ao enunciar S e o que $\mathrm{F}$ significou ao enunciar $\mathrm{S}$ naquela ocasião e à tentativa de explicar como aquilo que $\mathrm{F}$ diz pode divergir do que $\mathrm{F}$ quis dizer.

A fim de definir a natureza do significado, Grice propôs que deve ser possível explicar o significado de uma expressão em termos daquilo que os usuários da língua querem dizer, ou significam-nn (GRICE, 1975a), com um enunciado expresso em uma determinada ocasião. Ao distinguir o que chamou de significado natural de significado não natural, ou significado-nn, Grice sugeriu, essencialmente, que a constituição do significado também depende do falante (F), que tem a intenção de causar no receptor $(\mathrm{R})$ um determinado efeito, de modo que esse pense ou faça algo, a partir do reconhecimento da intenção do falante (F).

Ao aprofundar a análise das circunstâncias da conversação, Grice (1975b) propôs que em todas as situações comunicativas, somos orientados por princípios e regras de conversação, sem que tenhamos consciência disso. Essas regras de conversação, por sua vez, são orientadas pelo Princípio da Cooperação (PC), segundo o qual, o falante deve fazer sua contribuição conversacional da forma como é requerida, no momento em que ocorre, através do propósito ou direção aceitos no intercâmbio de fala no qual estiver engajado. O PC é articulado com quatro grandes categorias: qualidade, quantidade, relação e modo. E é pelo respeito ou pela violação dessas categorias que, segundo Grice, pode-se explicar como se dá a comunicação explícita. 
A TIG não explica as particularidades da produção de implicaturas a partir de enunciados metafóricos, especificamente. Mas aponta diretrizes em favor de uma análise da metáfora levando em conta a intenção comunicativa, e não somente o conteúdo da sentença. Para Grice, os enunciados metafóricos são casos de violação da máxima de qualidade, pois, se um falante $(\mathrm{F})$ proferir uma falsidade óbvia, o receptor $(\mathrm{R})$ está autorizado a inferir que, se $\mathrm{F}$ estiver cooperando para que a comunicação se estabeleça, $\mathrm{F}$ não pode estar querendo transmitir o que o significado literal da sentença expressa, motivo pelo qual $\mathrm{R}$ pode concluir que $\mathrm{F}$ deve estar querendo implicar algo diverso.

Ainda que Grice não tenha, necessariamente, pretendido desenvolver uma teoria da metáfora, sua contribuição foi evidente para o desenvolvimento de outras hipóteses acerca do processamento desse tipo de enunciado. ${ }^{2}$

Na esteira desse movimento, e absorvendo o modelo da TIG, Sperber e Wilson $(1991 ; 1995)$ formularam uma teoria ainda mais sofisticada na tentativa de explicar o fenômeno da inferência humana, numa interface cognitiva. Para tanto, na Teoria da Relevância (TR), elucidaram as razões pelas quais a hipótese griciana para o processamento de enunciados metafóricos não poderia, segundo os autores, estar certa.

Sperber e Wilson procuraram explicar o fenômeno da metáfora a partir da ideia de relevância subjacente a sua teoria. Pelo Princípio da Relevância (PR), cuja definição norteia a TR, entende-se que cada situação de comunicação ostensiva comunica sua própria relevância ótima (SPERBER; WILSON, 1995, p. 158). Subjacentes a esse princípio estão duas premissas que dizem respeito às noções de efeito cognitivo e de esforço de processamento: quanto maior o efeito cognitivo obtido pelo processamento de alguma informação e menor o esforço para fazê-lo, maior será a relevância ao indivíduo que a processa. Então, segundo essa ideia de custo/benefício, de um lado, temos o pressuposto de que, em uma situação comunicativa, se busque o máximo de benefício e, de outro, que esse benefício se dê a partir do menor esforço de processamento.

Para compreender o tratamento dado às metáforas na TR, é preciso primeiramente compreender o conceito de similaridade adotado pelos autores. De acordo com esse conceito, a questão da semelhança está relacionada ao grau de proximidade entre um enunciado e o conceito expresso por ele. Então, um enunciado literal e um enunciado metafórico só diferem quanto ao grau de

2 Sugerimos a leitura de Searle (1991), para aprofundar o paradigma griciano. 
vaguidade: um enunciado literal, nesse modelo, é o caso limite de semelhança máxima entre a proposição do enunciado e a proposição do pensamento do falante. Já os enunciados metafóricos seguiriam o mesmo princípio, porém distanciando o dito e o pensamento do falante num grau de vaguidade maior. Nesse caso, a forma proposicional do enunciado compartilha algumas propriedades lógicas, mas não todas, com a forma proposicional do pensamento que representa. Assim, a literalidade, ou identidade entre formas proposicionais, não representa a norma, mas um limite de semelhança máxima entre o enunciado e o pensamento do falante.

Sob essa perspectiva, não há razão, portanto, para supor que a mais relevante interpretação de um enunciado será sempre aquela com sentido literal, já que o objetivo da comunicação é a busca da maior relevância, com menor esforço. Por isso, para os teóricos da relevância, as metáforas não fogem a normas nem violam máximas de conversação, conforme propunha Grice, mas seguem exatamente os mesmos caminhos inferenciais que qualquer outro enunciado.

$\mathrm{Na}$ seara da TR, muitos estudiosos procuraram refinar essa concepção. Uma das propostas decorrentes desse entendimento foi apresentada por Carston (2002), que verificou uma certa assimetria na produção de significados metafóricos, apontando que esse processo cognitivo requer ora ajustamento (narrowing), ora alargamento (broadening) de conceitos. ${ }^{3}$ Segundo a autora, em decorrência desse processo, cada enunciado metafórico implicaria a formação de um conceito ad hoc, único e específico para cada situação contextual.

A fim de detalhar esse processo, a autora apresenta o seguinte exemplo:

(1) [Você e seu colega de trabalho, Roberto, têm visões diferentes em relação ao desenvolvimento de um plano de ação em sua empresa. Entretanto, você reluta em comentar seu ponto de vista, argumentando:] Roberto é um trator. ${ }^{4}$

Para compreender o significado de (1), o ouvinte precisa acessar as entradas enciclopédicas de Roberto e trator, que normalmente não aparecem juntas em uma relação sujeito/predicado. Para o ouvinte, a relevância de (1) depende dos efeitos contextuais produzidos na formulação de implicaturas. Nesse caso, não há uma implicatura mais forte que emerge do enunciado, à primeira vista, mas um conjunto de implicaturas como as apresentadas a seguir:

3 Dada a natureza constrita desse texto, não serão abordadas as especificidades do processo de ajustamento e de alargamento de conceitos. Para aprofundar a questão, ver Carston (2002), Wilson e Carston (2006), Sperber e Wilson (2008) e Wilson e Sperber (2012).

4 Robert is a bulldozer (CARSTON, 2002, p. 85; WILSON; CARSTON, 2006, p. 17). 
(1)

(a) Roberto é obstinado.

(b) Roberto é insensível.

(c) Roberto é teimoso.

(d) Roberto se recusa a cometer um desvio em seu caminho.

Então, TRATOR passa a significar $a d$ hoc TRATOR*, ${ }^{5}$ implicando OBSTINAÇÃO, INSENSIBILIDADE E TEIMOSIA.

O problema que emerge desse exemplo é o fato de que, se a produção de implicaturas depende do conhecimento enciclopédico de trator, de que modo são produzidas as implicaturas acima, já que conceitos de OBSTINAÇÃO, INSENSIBILIDADE e TEIMOSIA não podem ser associados ao conceito de TRATOR? ${ }^{6}$ Apenas seres humanos podem ter essas características psicológicas, máquinas não. Segundo a autora, intuitivamente, propriedades humanas de ROBERTO interagem com propriedades de TRATOR, de modo que são produzidas diferentes propriedades que podem ser plausivelmente aplicadas como predicação de Roberto e que são partilhadas pelo conceito ad hoc TRATOR*, específico desse contexto.

Para Wilson e Carston (2006), uma explicação possível para o fato de o ouvinte conseguir compreender enunciados como (1), a partir do alargamento do conceito TRATOR, reside na ideia de que as pessoas conseguem produzir analogias entre elementos que aparentemente não têm propriedades em comum. Seria preciso, segundo as autoras, mapear propriedades emergentes entre TRATOR e PESSOAS OBSTINADAs. ${ }^{7}$ Por essa razão, para processar um enunciado metafórico, o ouvinte deverá acessar uma área mais ampla de conhecimento, o que, provavelmente, gerará um maior número de implicaturas para esses enunciados.

Como resultado, a produção de conceitos ad hoc também dependerá da relevância percebida pelo ouvinte e, em alguns casos, é possível que um mesmo elemento lexical produza diferentes conceitos ad hoc, como o que acontece a

5 Conceitos lexicais serão indicados por versaletes; conceitos $a d$ hoc, por versaletes e asteriscos.

6 Ver aprofundamento dessa discussão em Romero e Soria (2014).

7 Nas versões mais atuais da TR (SPERBER; WILSON, 2008; WILSON; SPERBER, 2012), entretanto, reconheceu-se que há um problema circular a ser resolvido pelo fato de se incorporarem conceitos $a d$ hoc na explicação da compreensão da metáfora: o problema das propriedades emergentes (WILSON; CARSTON, 2006), ou seja, da indeterminação dos conceitos ad hoc. Em outras palavras, para se configurarem conceitos ad hoc, como TRATOR*, é preciso que se evoquem propriedades emergentes como OBSTINAÇÃO*, também ad hoc ao contexto. E, assim, um conceito ad hoc será formado por propriedades emergentes ad hoc. Essa é a questão central da TR no momento, mas não será tratada neste texto, porque não pretendemos discutir a TR em suas especificidades. 
partir de trator: TRATOR*, TRATOR**, TRATOR***, e assim por diante (WILSON; SPERBER, 2012).

Nesta seção, a metáfora foi desenhada no paradigma da Pragmática. Apresentados os principais fundamentos da TIG e da TR, evidenciou-se que ambas divergem essencialmente no entendimento da natureza das inferências decorrentes de enunciados metafóricos. A seguir, apresentaremos a metáfora sob o viés da Neurociência.

\section{A metáfora no cérebro: a anatomia da linguagem metafórica}

Por serem relativamente recentes, se comparados a uma tradição aristotélica de estudos da linguagem natural, os estudos linguísticos com neuroimagem ainda têm uma tradição a consolidar. Em relação às pesquisas acerca do processamento da metáfora, por exemplo, há achados distintos, o que implica dificuldades na formulação de uma teoria da metáfora de base neurológica. Além disso, aspectos contextuais e intencionalidades do falante, centrais em uma abordagem da metáfora via pragmática, são, segundo Ferstl (2012), variáveis complexas no desenho de experimentos a serem testados com neuroimagem, pois características cognitivas individuais, como a manipulação de conhecimentos prévios ou o controle das variáveis contextuais em cada situação enunciativa decorrem justamente de especificidades pragmáticas e são difíceis de controlar em laboratórios.

Por essa complexa configuração, os achados com neuroimagem a respeito do processamento da metáfora apontam para diferenças anatômicas no recrutamento de regiões cerebrais tanto no hemisfério esquerdo (HE), quanto no hemisfério direito (HD).

Reconhece-se, a despeito dessa diversidade, uma tese consensual acerca do processamento de enunciados metafóricos. Segundo Ferstl (2012, p. 79), há maior engajamento de correlatos neurais no HD quando os indivíduos têm de dar sentido a um enunciado metafórico. Entretanto, há paradoxalmente evidências distintas em relação à participação do HD na compreensão de metáforas: se decorrentes de sentenças simples ou de enunciados contextualmente complexos, os achados diferem tanto em termos de recrutamento de hemisférios, quanto em termos de regiões corticais recrutadas em cada hemisfério. Isso porque, ainda segundo Ferstl (2012), há diferenças nos procedimentos experimentais adotados e nos correlatos neuronais analisados nesses estudos. 
Entendemos, entretanto, que tais distinções ocorrem menos em função das hipóteses anatômicas e mais em função dos fundamentos epistemológicos linguísticos subjacentes às metodologias empregadas nos experimentos. Em termos linguísticos, destacam-se alguns aspectos sobre os quais não há consenso nos estudos com fMRI: o que são traços semânticos e pragmáticos e sob que fundamentos filosóficos são entendidos; qual é a natureza do pensamento analógico e como se desenham, em termos teóricos, as analogias tipicamente referenciadas em estudos da metáfora; quais as correlações semânticas entre metáforas mais ou menos convencionais e por que se concretizam em correlatos neurais distintos. $\mathrm{Na}$ próxima seção, trataremos mais especificamente dessa questão.

A fim de desenhar a metáfora na perspectiva neurocientífica, selecionamos neste estudo a coarse-coding hypothesis (BEEMAN, 1998; JUNG-BEEMAN, 2005), que, embora não seja a única hipótese de base neurológica nos estudos com fMRI, tem maior impacto nas discussões acerca do engajamento dos hemisférios no processamento da linguagem. Feita essa opção metodológica, apresentaremos três estudos com neuroimagem para, a seguir, tecermos algumas considerações a respeito dos achados apresentados.

Segundo Beeman (1998), o processamento da linguagem pode ser mais focal e refinado (fine coding) ou mais abrangente e "grosseiro" (coarse coding). No primeiro caso, o HE seleciona rapidamente os significados relevantes, focando na construção de aproximadas associações de sentido, o que implica uma ativação cortical restrita; no segundo caso, o HD é recrutado fracamente e em amplo espectro, quando há significados difusos e associações mais distantes. Ou seja, a natureza da recuperação das relações semânticas é que determinará o tipo de ativação que o cérebro terá. Sob essa hipótese, o recrutamento do HD estaria associado ao aumento da complexidade de processamento (JUNG-BEEMAN, 2005).

Em relação ao processamento da metáfora, os estudos fundamentados nessa hipótese defendem o argumento de que o HD tem papel fundamental especialmente na compreensão de metáforas não convencionais (ou criativas), aquelas em que os itens comparados têm poucas propriedades semânticas em comum. Nesse caso, o HD seria recrutado a fim de se estabelecerem as propriedades semânticas entre eles. Mais especificamente, ao HD caberiam as funções de acessar as categorias semânticas dos elementos em comparação e selecionar as mais adequadas ao contexto, enquanto ao $\mathrm{HE}$ caberia a função de correlacionar os conceitos evocados e integrá-los conceitualmente (FERSTL, 2012, p. 59). 
Três experimentos com neuroimagem apontam para essa hipótese: Rapp et al. (2004), Shibata et al. (2007) e Lai et al. (2015).

O estudo proposto por Rapp et al. (2004) se fundamentou na hipótese de que o processamento de sentenças metafóricas, em contraste com sentenças literais, resultaria na ativação do córtex temporal lateral direito. O procedimento consistia em solicitar aos 15 sujeitos participantes, falantes nativos de alemão, que julgassem o grau de conotação de 60 sentenças, 30 literais e 30 metafóricas, randomicamente apresentadas. As sentenças foram construídas tomando como critério sua ocorrência ou não no dicionário Duden. Então, uma sentença como 'As palavras de amor são mentiras' foi assumida com literal, e a sentença 'As palavras de amor são sons de harpa' foi classificada como metafórica. Os resultados, calculados por contraste entre as sentenças metafóricas e literais, indicaram uma alta ativação do giro frontal inferior esquerdo, do giro inferior temporal e do giro temporal inferior e medial posterior esquerdo. Ou seja, os achados revelaram ativação somente no HE. Para os autores, portanto, o envolvimento do HD no processamento de metáforas não é essencial como pressuposto, inclusive, por Jung-Beeman (2005).

O estudo de Shibata et al. (2007) tinha o propósito de descrever os correlatos neurais para o processamento da metáfora em japonês. Os autores assumiram duas hipóteses: a de que o processamento de sentenças literais e metafóricas envolve substratos neurais distintos e a de que o HD tem participação essencial nesse processo. $\mathrm{O}$ experimento se deu a partir da seleção de 63 sentenças do tipo A é um $\mathrm{B}$, das quais 21 eram literais (O golfinho é um animal), 21 metafóricas (A verdade é um labirinto) e 21 anômalas (As tesouras são cachorros). Cada participante teve de julgar as sentenças que lhe eram apresentadas randomicamente, indicando se as havia compreendido ou não, enquanto imagens com fMRI eram coletadas. Durante o processamento de sentenças com metáforas, segundo os achados, foi fundamental a atuação do HE, em especial as regiões do córtex frontal inferior, responsável pelo processamento semântico. Com relação à ativação do HD, foi recrutado o córtex frontal medial bilateral, envolvido no processamento das metáforas, em razão do estabelecimento, segundo os autores, da coerência entre A e B, nas sentenças como 'A verdade é um labirinto'. A essa região, em especial, costuma-se atribuir funções de julgamento pragmático que se constitui em cada situação de uso. Aparentemente contraditório, uma vez que o estudo se deteve no nível da sentença e não do enunciado, esse achado, segundo os autores, pode indicar, mais do que um aspecto pragmático, a particular natureza da testagem, já 
que os participantes tinham de estabelecer julgamentos para cada sentença. Além disso, verificou-se maior ativação do córtex bilateral pré-frontal dorsolateral, apenas durante o processamento das metáforas, o que indicou maior esforço cognitivo. Além desse aspecto anatômico, outra evidência corroborou maior esforço no processamento de metáforas: o tempo de processamento a fim de atingir a coerência semântica.

O terceiro estudo selecionado para esta análise é o de Lai et al. (2015). Tomando como referência outros estudos com fMRI, os pesquisadores procuraram verificar o papel efetivo do HD no processamento de enunciados metafóricos e literais. Para tanto, partiram do pressuposto de que a familiaridade dos enunciados tem papel central na necessidade ou não de engajamento do HD. Ou seja, como metáforas não convencionais ou sentenças não familiares em geral demandam maior esforço de processos executivos, como reanálises, memória de trabalho, inibição, atenção e tomadas de decisão, segundo a hipótese dos autores, tais processos demandam maior engajamento de regiões do cérebro. Assim, a participação do HD no processamento da linguagem dependeria mais do grau de dificuldade do enunciado do que necessariamente de algum aspecto como figuratividade. O estímulo consistiu em 81 grupos de três sentenças, incluindo uma metafórica (The jury grasped the concept), uma abstrata (The jury understood the concept) e uma literal (The daughter grasped the flowers), em que o verbo indicasse uma ação. Os participantes tiveram de avaliar cada sentença, em uma escala em que 1 indicasse pouca familiaridade e 7 alta familiaridade. Os achados revelaram que à medida que diminuía a escala de familiaridade aumentava a ativação tanto no HE quanto no HD. Sentenças familiares ativaram regiões tipicamente acessadas no processamento da linguagem no HE. Sentenças totalmente não familiares, independentemente de serem metafóricas ou não, aumentaram a ativação de regiões do $\mathrm{HE}$, além recrutarem algumas regiões do $\mathrm{HD}$, como o giro frontal inferior direito, giro frontal medial direito e ínsula. Segundo os autores, esses padrões de ativação frequentemente sinalizados em estudos prévios como indicadores de processamento de metáforas, neste estudo revelaram que o aumento da ativação no HD indicava aumento da dificuldade do processamento cognitivo, dada a natureza do estímulo, e não necessariamente que o enunciado a ser processado fosse metafórico.

A seguir, apresentamos um resumo dos achados. 
QUADRO 1 - Resumo dos achados

\begin{tabular}{|c|c|c|c|c|}
\hline & Estímulo & Tarefa & $\begin{array}{l}\text { Achados } \\
\text { anatômicos }\end{array}$ & Conclusões \\
\hline $\begin{array}{l}\text { Rapp } \\
\text { et al. } \\
\text { (2004) }\end{array}$ & $\begin{array}{l}\text { Sentenças } \\
\text { literais e } \\
\text { metafóricas }\end{array}$ & $\begin{array}{l}\text { Julgar o grau de } \\
\text { conotatividade } \\
\text { (positivo ou } \\
\text { negativo) das } \\
\text { sentenças }\end{array}$ & $\begin{array}{l}\text { - giro frontal } \\
\text { inferior esquerdo } \\
\text { - giro inferior } \\
\text { temporal } \\
\text { - giro temporal } \\
\text { inferior e medial } \\
\text { posterior esquerdo }\end{array}$ & $\begin{array}{l}\text { Como não houve } \\
\text { ativação do HD, } \\
\text { não se pode } \\
\text { afirmar que há } \\
\text { envolvimento } \\
\text { de correlatos } \\
\text { neurais do HD no } \\
\text { processamento da } \\
\text { metáfora. }\end{array}$ \\
\hline $\begin{array}{l}\text { Shibata } \\
\text { et al. } \\
(2007)\end{array}$ & $\begin{array}{l}\text { Sentenças } \\
\text { literais, } \\
\text { metafóricas } \\
\text { e anômalas }\end{array}$ & $\begin{array}{l}\text { Indicar se havia } \\
\text { compreendido a } \\
\text { sentença }\end{array}$ & $\begin{array}{l}\text { - córtex bilateral } \\
\text { pré-frontal } \\
\text { dorsolateral } \\
\text { - córtex frontal } \\
\text { inferior esquerdo } \\
\text { - córtex frontal } \\
\text { medial bilateral }\end{array}$ & $\begin{array}{l}\text { Os enunciados } \\
\text { metafóricos são } \\
\text { processados } \\
\text { essencialmente } \\
\text { pelo } \\
\text { HE, mas o HD é } \\
\text { recrutado quando } \\
\text { há necessidade de } \\
\text { complementação } \\
\text { do sentido e de } \\
\text { correlação entre } \\
\text { conceitos. }\end{array}$ \\
\hline $\begin{array}{l}\text { Lai } \\
\text { et al. } \\
(2015)\end{array}$ & $\begin{array}{l}\text { Sentenças } \\
\text { literais, } \\
\text { metafóricas } \\
\text { e abstratas }\end{array}$ & $\begin{array}{l}\text { Avaliar o grau } \\
\text { de familiaridade } \\
\text { da sentença em } \\
\text { uma escala de } \\
1 \text { a } 7\end{array}$ & $\begin{array}{l}\text { - giro frontal } \\
\text { inferior direito } \\
\text { - giro frontal } \\
\text { medial direito } \\
\text { - ínsula }\end{array}$ & $\begin{array}{l}\text { Os padrões } \\
\text { de ativação } \\
\text { revelaram que } \\
\text { o aumento da } \\
\text { ativação no HD } \\
\text { indica aumento } \\
\text { da dificuldade do } \\
\text { processamento } \\
\text { cognitivo, dada } \\
\text { a natureza do } \\
\text { estímulo, e não } \\
\text { necessariamente } \\
\text { que o enunciado } \\
\text { a ser processado } \\
\text { fosse metafórico. }\end{array}$ \\
\hline
\end{tabular}

Fonte: Elaboado pelos autores. 
Nesta seção apresentaram-se as bases anatômicas comumente referenciadas em estudos com neuroimagem sobre a metáfora. Evidenciou-se pouca ativação no $\mathrm{HD}$, muito embora a hipótese em jogo nos experimentos apresentados pressupusesse o recrutamento de regiões homólogas às da linguagem no HE também no HD. Todos os estudos, no nível da sentença, parecem apontar para uma característica assinalada em apensas um dos experimentos: o recrutamento do HD parece depender mais do grau de dificuldade no estabelecimento da correção semântica entre tópico e veículo do que, necessariamente, de uma propriedade como literalidade ou metaforicidade.

Na próxima seção, discutiremos essa questão.

\section{A metáfora na mente e no cérebro: delimitando a interface}

Um dos problemas comuns, em se tratando da aproximação de fundamentos teóricos distintos, é o ajustamento metateórico na composição de estudos interdisciplinares.

Dois problemas são apresentados por Poeppel e Embick (2005) como sendo decorrentes de propostas dessa natureza. O primeiro é o problema da incompatibilidade granular, segundo o qual disciplinas de natureza distinta lidam com escopos de granularidade igualmente distinta. É o caso do diálogo que aqui se propõe, pois a Pragmática lida com enunciados e conceitos, enquanto a Neurociência lida com regiões corticais e ativação de neurônios. O segundo, o da incomensurabilidade ontológica, aponta para a natureza dos objetos de investigação: se forem desenhados dentro de um campo teórico, assumem as propriedades dessa teoria, o que inviabiliza sua avaliação fora do escopo no qual foram concebidos. Para resolver esses problemas, a Metateoria das Interfaces, tal como proposta por Costa (2007), indica uma solução viável: a proposição de objetos terceiros, multiformes e multivalentes, desenhados na aproximação de disciplinas e que, por essa razão, partilham propriedades comuns às disciplinas em diálogo (COSTA, 2007, p. 348).

A seguir, ilustra-se essa proposta. Para tanto, retomemos as questões que nortearam o presente estudo: em que medida os fundamentos linguísticos têm sido utilizados como ponto de partida para delinear os experimentos com fMRI? E, em contrapartida, em que medida os estudos com neuroimagem podem reacender o diálogo entre hipóteses defendidas pela tradição linguística? 
Com relação à primeira questão, na interface metateórica podem ser tecidas algumas considerações, a partir dos exemplos apresentados nos estudos mencionados:

(2) As palavras de amor são sons de harpa. (RAPP et al., 2004)

(3) A verdade é um labirinto. (SHIBATA et al., 2007)

(4) The jury grasped the concept. (LAI et al., 2015)

Como os experimentos partiram de sentenças desvinculadas do contexto, aos participantes coube acessar de sua memória enciclopédica as propriedades comumente acessadas quando tais conceitos são empregados. Então, na perspectiva da Teoria da Relevância, HARPA*, LABIRINTO* e TO GRASP* ativam, respectivamente, as propriedades ad hoc emergentes [BELA SONORIDADE]*, [DE DIFíCIL ACESSO]* e COMPREENDER*. ${ }^{8}$ Todas essas propriedades estão na entrada lexical dos conceitos HARPA, LABIRINTO e TO GRASP e são facilmente associadas aos tópicos das sentenças: PALAVRAS, VERDADE e JÚRI. Não há nenhuma pista contextual que implique um grau de dificuldade na formação desses conceitos. Decorre que, sob o paradigma da coarse-coding hypothesis, o HD será recrutado quando for necessária a recuperação de relações semânticas mais distantes entre tópico e veículo. Mas não é o caso de nenhum dos três exemplos. Por isso, houve pouca ativação dos correlatos neurais no HD nos três experimentos relatados.

Não se pode, portanto, com base nesses experimentos, afirmar que o processamento da metáfora se dá mais no $\mathrm{HE}$ ou no $\mathrm{HD}$, porque a escolha dos exemplos empregados não se fundamentou em paradigmas linguísticos. Se assim ocorresse, outros exemplos em que tópico e veículo efetivamente não compartilham nenhuma propriedade semântica deveriam ser selecionados, especialmente para serem gerados conceitos ad hoc com propriedades semânticas não convencionais. Somente assim, provavelmente, o HD seria ativado.

Cabe salientar, entretanto, que em Lai et al. (2015) os achados revelaram maior ativação nos giros frontal inferior direito e frontal medial direito, além da ínsula, especialmente quando os participantes processavam as sentenças com menor familiaridade, o que confirma a hipótese linguística que estamos defendendo: o ouvinte deverá acessar por ordem de relevância as propriedades semânticas que julgar mais relevantes, dado o contexto linguístico. O tempo e o grau de dificuldade de processamento são decorrentes do grau de vaguidade entre o enunciado e o

8 No dicionário Oxford constam as acepções: hold firmly e understand fully. Disponível em: $<\underline{\text { http: } / / \text { www. }}$ oxforddictionaries.com/pt/defini $\% \mathrm{C} 3 \% \mathrm{~A} 7 \% \mathrm{C} 3 \% \mathrm{~A} 3 \mathrm{o} / \mathrm{ingl} \% \mathrm{C} 3 \% \mathrm{AAs} /$ grasp? searchDictCode=all $>$. Acesso em: 20 mar. 2016. 
conceito complexo que emerge desse enunciado. Caberá ao indivíduo parar a busca quando julgar ter atingido a relevância ótima para a formação do conceito $a d$ hoc. E é por essa complexidade de processamento que o HD poderá ser recrutado.

Com relação à segunda questão, é possível lançarmos algumas considerações em nível teórico.

Do ponto de vista anatômico, os achados revelaram: a) que o tempo de processamento de enunciados metafóricos é maior que o de enunciados não metafóricos; b) que enunciados metafóricos podem recrutar regiões corticais distintas, se comparados aos enunciados não metafóricos; c) que enunciados que demandam integração semântica complexa são processados no HD, confirmando a coarse-coding hypothesis.

Aparentemente, do ponto de vista do cérebro, a participação do HD está mais condicionada ao grau de convencionalidade da metáfora. Ou seja, quanto mais convencional o significado, menor será a necessidade de recrutamento de regiões cerebrais.

E em que esses achados contribuem para o diálogo entre teorias linguísticas, como a Teoria das Implicaturas, de Grice, e a Teoria da Relevância, de Sperber e Wilson?

Lai et al. (2015, p. 8) sinalizam que "it is possible that RH involvement changes for highly unfamiliar metaphors" e sugerem que essa questão merece outro tipo de análise.

Suponhamos que estejam certos e assumamos a hipótese de que há diferença de recrutamento para metáforas convencionais - como as apresentadas nos experimentos - e metáforas não convencionais.

Voltemos aos exemplos já mencionados:

(1) Roberto é um trator.

(3) A verdade é um labirinto.

Parece-nos que esses exemplos podem ter processos de compreensão distintos, evidenciados pelos achados em neuroimagem.

Para o caso das metáforas em (1) e (3), pelo Princípio da Relevância (PR) é preciso, como se afirmou, acessar propriedades ou traços emergentes comuns entre ROBERTO e TRATOR, a fim de se compor o conceito ad hoc TRATOR*, e entre VERDADE e LABIRINTO, para compor LABIRINTO*.

No contexto de (3), o traço emergente mais evidente parece ser [DE DIFÍCIL ACESSO]*. Os achados com neuroimagem indicam que metáforas como 
são processadas preferentemente pelo $\mathrm{HE}$, no giro frontal inferior esquerdo, possivelmente porque [DE DIFíCIL ACESSO]* é o traço mais relevante a ser acessado, que dá conta, por ele mesmo, da produção de sentido de LABIRINTO*. Ou seja, numa perspectiva griciana, S, P e R partilham a mesma propriedade: [DE DIFÍCIL ACESSO]*. Trata-se, portanto, de uma metáfora convencional.

Entretanto, o mesmo não ocorre em (1), porque de TRATOR não decorrem naturalmente propriedades emergentes ligadas ao comportamento das pessoas como OBSTINAÇÃO, INSENSIBILIDADE e TEIMOSIA, como se afirmou anteriormente. Segundo a TR, é por ordem de acessibilidade que essas propriedades são acessadas. Mas quanto mais distantes do veículo, nesse caso, TRATOR, maior será o custo de processamento para acessá-los. Do ponto de vista neurológico, nesses casos o HD passa a ser recrutado para, via coarse-coding hypothesis, garantir a integração semântica entre os conceitos. Aparentemente, o funcionamento do cérebro parece indicar, no caso de metáforas menos convencionais como (1), que o ouvinte deve reconhecer, primeiro, que as propriedades emergentes a serem acessadas não pertencem ao conceito convencional do veículo. Em outras palavras, o ouvinte precisa reconhecer que, para produzir TRATOR*, deve buscar traços emergentes não convencionalmente implicados do conceito TRATOR, como OBSTINAÇÃO, por exemplo. Para essa integração semântica, o HD precisa ser recrutado, pois há maior custo de processamento.

Nesse caso, então, pode-se afirmar que faz sentido supor que o ouvinte deve primeiro reconhecer que, se tomado como convencional, nos termos de Grice, o enunciado não será compreendido. É preciso que o ouvinte reconheça, portanto, que a produção de sentido de 'Roberto é um trator' depende de um outro tipo de reconhecimento conceitual não convencional, produzido a partir do que Grice chamou de violação da máxima de qualidade. Se o falante estiver seguindo o Princípio da Cooperação, trator deverá implicar, no contexto de (1), propriedades emergentes cujas condições de verdade, ainda nos termos de Grice, não podem ser associadas convencionalmente ao conceito TRATOR. Ou seja, para processar (1), o ouvinte reconhece a violação e precisa recrutar o HD para contribuir na composição do conceito TRATOR*.

Além disso, na perspectiva da interface, a relevância do enunciado não está, de fato, na literalidade. Ao contrário. Mais relevante para o ouvinte é, apesar do alto custo de processamento, tanto em termos cognitivos quanto neurológicos, reconhecer que o enunciado é falso e passar a processá-lo como tal. Uma das fortes 
críticas ao argumento griciano é que não haveria razão para o ouvinte ter de, a fim de processar todos os enunciados metafóricos, reconhecer o sentido literal para, depois, implicar o sentido metafórico. Em se tratando de metáforas convencionais, esse argumento se sustenta. Mas, em se tratando de metáforas não convencionais, os achados com neuroimagem parecem apontar para o argumento defendido por Grice.

Do ponto de vista neurocientífico, a descrição dos correlatos neurais acessados durante o processamento de enunciados metafóricos induz a novas possibilidades de tratamento teórico da metáfora. Do ponto de vista linguístico, esses achados indicam a possibilidade de se reacenderem os diálogos entre as teorias.

\section{Considerações finais}

Neste estudo, pretendeu-se complexificar o tratamento teórico da metáfora, numa perspectiva teórica e metateórica.

Do ponto de vista metateórico, ao desenharmos a metáfora na interface, por meio de relações interdisciplinares, como sugeridas pela Metateoria das Interfaces (COSTA, 2007), pretendíamos contribuir para ilustrar a possibilidade de se desenharem novos paradigmas de tratamento dos objetos de investigação. Linguística e Neurociência em diálogo podem garantir novos olhares para o estudo da metáfora, já que, na interface, novas abordagens são possíveis.

Do ponto de vista teórico, elucidamos como disciplinas de escopo distinto, se postas em diálogo, contribuem para a própria revitalização de hipóteses divergentes. Ao desenharmos um objeto terceiro, qual seja, a metáfora na interface, trouxemos para o campo da Neurociência problematizações linguísticas e vice-versa. Decorre disso que teorias linguísticas abandonadas podem ter sobrevida se assumidas nas fronteiras interdisciplinares.

Cabe, numa reflexão final, aludir ao fato de que, dada a natureza complexa da metáfora, o viés de análise, como se propôs aqui, não pode se esgotar em si mesmo. Se assim fosse, facilmente se incorreria numa contradição ontológica em relação ao argumento central aqui sustentado. Isso porque se argumentou em favor da interface entre disciplinas, a partir da qual novos objetos são construídos, assumindo propriedades mais complexas. Dessa forma, o que se sustenta aqui é uma provocação a novos olhares e novas reflexões. 


\title{
Metaphor is dialogue: an interface proposal
}

\begin{abstract}
In this study, we intend to draw a metaphor approach in a meta-theoretical interface (COSTA, 2007). We intend to illustrate how, through in an interdisciplinary dialogue, new approaches to a metaphor analysis can be constructed. For this purpose, on the one hand, we present the foundations of Pragmatics that explain how we process the metaphorical utterances; and, on the other, we present findings from Neuroscience which describe, through coarse-coding hypothesis, the neural correlates of this processing. Put into dialogue, complex properties emerge from these different areas and may contribute to the deepening of the descriptive and explanatory potential of an interdisciplinary approach. Besides, from this interface we also can relight and complexify the possibilities of dialogue between theories, when complex properties interact.
\end{abstract}

Keywords: Metaphor. Metatheory of interfaces. Theory of Conversational Implicature. Relevance Theory. Neuroscience.

\section{Referências}

BEEMAN, Mark. Coarse semantic coding and discourse comprehension. In: BEEMAN, Mark Jung; CHIARELLO, Christine. Right hemisphere language comprehension: perspectives from cognitive neuroscience. Mahwah, NJ: Lawrence Erlbaum, 1998. p. 225-284.

CARSTON, Robin. Metaphor, ad hoc concepts and word meaning. UCL working papers in linguistic, n. 14, p. 83-105, 2002.

COSTA, Jorge Campos da. The sciences of language: communication, cognition and computation. In: AUDY, Jorge L.; MOROSINI, Marília (Org.). Inovação e Interdisciplinaridade na Universidade. Porto Alegre: EDIPUCRS, 2007. p. 273-304.

DAVIDSON, Donald. What metaphors mean. In: DAVIDSON, Donald. Inquiries into truth and interpretation. Oxford: Clarendon Press, 1984. p. 245-264.

FERSTL, Evelyn C. The functional neuroanatomy of text comprehension: what's the story so far? In: SCHMALHOFER, Franz; PERFETTI, Charles A. Higher Level Language in the Brain: Inference and Comprehension Processes. London: Psychology Press, 2012. p. 53-102.

GRICE, Herbert Paul. Meaning. In: STEINBERG, Danny; JAKOBOVITS, Leon. Semantics: an interdisciplinary reader in philosophy, linguistics and psychology. 
Cambridge: Cambridge University Press, 1975a. p. 52-65. Original publicado em 1957.

GRICE, Herbert Paul. Logic and conversation. In: COLE, Peter; MORGAN, Jerry (Ed.). Syntax and semantics. New York: Academic Press, 1975b. v. 3, p. 41-58.

JUNG-BEEMAN, Mark. Bilateral brain processes for comprehending natural language. Trends in Cognitive Science, n. 9, p. 712-718, 2005.

LAI, Vicky T.; VAN DAM, Wessel; CONANT, Lisa L.; BINDER, Jeffrey R.; DESAI, Rutvik H. Familiarity differentially affects right hemisphere contributions to processing metaphors and literals. Frontiers in Human Neuroscience, v. 9, p. 1-10, 2015.

NEALE, Stephen. Paul Grice and the philosophy of language. Linguistics and Philosophy, n. 15, p. 509-559, 1992.

POEPPEL, David; EMBICK, David. Defining the relation between linguistics and neuroscience. In: CUTLER, Anne. Twenty-First Century Psycholinguistics: Four Cornerstones. Mahwah, NJ: Erlbaum, 2005. p. 103-118.

RAPP, Alexander M.; LEUBE, Dirk T.; ERB, Michael; GRODD, Wolfgang; KIRCHER, Tilo T. J. Neural correlates of metaphor processing. Cognitive Brain Research, v. 20, n. 3, p. 395-402, 2004.

ROMERO, Ether; SORIA, Belén. Relevance Theory and metaphor. Linguagem em (Dis)curso - LemD, Tubarão - SC, v. 14, n. 3, p. 489-509, set./dez. 2014.

SEARLE, John R. Metaphor. In: DAVIS, Steven. Pragmatics: a reader. New York: Oxford University Press, 1991. p. 519-539. Original publicado em 1982.

SHIBATA, Midori; ABE, Jun-ichi; TERAO, Atsushi; MIYAMOTO, Tamaki. Neural mechanisms involved in the comprehension of metaphoric and literal sentences: An fMRI study. Brain Research, v. 1.166, p. 92-102, 2007.

SPERBER, Dan; WILSON, Deirdre. Loose talk. In: DAVIS, Steven. Pragmatics: a reader. New York: Oxford University Press, 1991. p. 540-549.

SPERBER, Dan; WILSON, Deirdre. Relevance: communication $\&$ cognition. $2^{\text {nd }}$ ed. Cambridge: Blackwell, 1995.

SPERBER, Dan; WILSON, Deirdre. A deflationary account of metaphors. In: GIBBS, Raymond. The Cambridge Handbook of Metaphor and Thought. Cambridge: Cambridge University Press, 2008. p. 84-105. 
WILSON, Deirdre; CARSTON, Robin. Metaphor, relevance and the 'emergent property' issue. Mind and Language, v. 21, n. 3, p. 404-433, 2006.

WILSON, Deirdre; SPERBER, Dan. Meaning and relevance. Cambridge: Cambridge University Press, 2012.

Recebido em 09/04/2016.

Aceito em 05/07/2016. 